\title{
Comparing the Effects of Inputs for NTT and ArcAPEX Interfaces on Model Outputs and Simulation Performance
}

\author{
Amanda M. Nelson*, Daniel N. Moriasi, Mansour Talebizadeh, Haile K. Tadesse, \\ Jean L. Steiner, Prasanna H. Gowda, Patrick J. Starks \\ USDA-ARS-Grazinglands Research Laboratory, El Reno, OK, US \\ Email: *Amanda.nelson@ars.usda.gov
}

How to cite this paper: Nelson, A.M., Moriasi, D.N., Talebizadeh, M., Tadesse, H.K., Steiner, J.L., Gowda, P.H. and Starks, P.J. (2019) Comparing the Effects of Inputs for NTT and ArcAPEX Interfaces on Model Outputs and Simulation Performance. Journal of Water Resource and Protection, 11, 554-580.

https://doi.org/10.4236/jwarp.2019.115032

Received: April 9, 2019

Accepted: May 19, 2019

Published: May 22, 2019

Copyright $\odot 2019$ by author(s) and Scientific Research Publishing Inc. This work is licensed under the Creative Commons Attribution International License (CC BY 4.0).

http://creativecommons.org/licenses/by/4.0/

\begin{abstract}
The Agricultural Policy/Environmental eXtender (APEX) model has five different interfaces used to process and build simulation projects. These interfaces utilize different input databases that lead to different model default values. These values can result in different hydrologic, crop growth, and nutrient flow model outputs. This study compared structural and input value differences of the ArcAPEX and Nutrient Tracking Tool (NTT) interfaces. Long-term, water quality data from the Rock Creek watershed, located in Ohio were used to determine the impact of the differences on computation time, parameter sensitivity, and streamflow, total nitrogen (TN), and total phosphorus (TP) simulation performance. The input structures were the same for both interfaces for all files except soils, where NTT assigns three soil files per field, rather than a single one in ArcAPEX. As a result, computation times were three times as long for NTT as for ArCAPEX. There were twelve sensitive parameters in both cases, but the order of sensitivity was different. Both interfaces simulated streamflow well, but ARCAPEX simulated evapotranspiration, TN, and TP better than NTT, while NTT simulated crop yields better than ArcAPEX. However, none of the models met all of the performance criteria for either interface. Therefore, more work is needed to ensure models are properly calibrated before being used for scenario analysis. While it is acceptable for the values to be different from the SSURGO database, there is no documentation explaining the rationale for the modifications from the original source. This is one of the examples that highlights lack of detailed documentation that would be useful to model users. Overall, the results indicate that different interfaces lead to different model simulation results and, therefore, the authors recommend users specify the interface used and any modifications made to the associated databases when reporting model results.
\end{abstract}




\section{Keywords}

Agricultural Policy Environmental eXtender (APEX), Calibration, Sensitivity Analysis, Parameterization, Model Databases

\section{Introduction}

Nutrient transport to water ways is of great concern to proper land management [1] [2]. Fertilizer application, usually a combination of nitrogen, phosphorus, and potassium, is one of the important inputs in crop production [3]. However, when nitrogen is overapplied or when the nitrogen use efficiency of a crop is low, the excess of nitrogen is transported to waterbodies or leached into groundwater, which can have far-reaching effects [1]. The effects include pollution such as water contamination and eutrophication of downstream sites, and nitrogen loss from the field and hence reduced nitrogen use efficiency of crop, and increased fertilizer costs to farmers [1] [4] [5]. Hydrologic and water quality models such as the Soil and Water Assessment Tool (SWAT) [6] and the Agricultural Policy/Environmental eXtender (APEX) [7] have been widely used to quantify the impacts of various management systems on water resources [8] [9] [10] [11] [12].

There are many studies comparing the impact of models [[12] [13], etc.], soil [[13] [14] [15] [16] [17], etc.] and weather [[17] [18], etc.] data sources, evapotranspiration (ET) calculation methods [19], and digital elevation model (DEM) resolutions [[20] [21], etc.] on model outputs, performance, and scenario results. However, based on the literature review, there are no studies that report the impact of the interfaces used to build models on model outputs and performance. Interfaces developed for hydrologic and water quality models are mainly used to pre-process data and create model input files for simulations [22] [23] [24]. However, different interfaces utilize different databases to derive model input. This can result in different default parameter values, which can lead to a different set of simulated outputs, conclusions, and recommendations. Model users choose an interface based on accessibility and ease of use and could benefit from a study that determines the potential impacts of the selected interface on model outcomes.

Models and interfaces utilize regional or national DEM, soils, and crop databases in order to provide default model input values for a given study area. Many studies present the advantages, disadvantages, and best methods of using databases in modeling [14] [15] [25] [26]. Some of these databases, such as soils and crop, may be modified by the model and interface developers based on the structure and possible quality assurance/quality control procedures. Although the developers give the users the option to modify the inputs, in most cases, model users don't have measured data, especially at the watershed scale, to adjust the default parameter values. Therefore, many studies use the default values obtained from 
these databases without modification [19] [21] [26] [27] [28] [29] [30].

The APEX [7] [8] model is a watershed simulation model used to assess the impact of land management practices on water flow, sediment, and nutrients. APEX is a direct extension of Environmental Policy Integrated Climate Model (EPIC) [31]. There are five different interfaces used to process and build APEX model projects, including ArcAPEX [32], iAPEX [33], WinAPEX [34], APEX for Linux (https://epicapex.tamu.edu/model-executables/), and the Nutrient Tracking Tool (NTT) [35] [36]. Each of these interfaces have been used for different applications [15] [20] [29]. Monks et al. [15] used WinAPEX to compare the effects of different soil datasets on streamflow, surface runoff, and crop yields in Washington state, while Nelson et al. used ArcAPEX to build projects to compare the effect of the length of calibration period on hydrologic outputs [28] and examining the need for soft data in the calibration process [29]. Tadesse et al. [19] used NTT to compare the different evapotranspiration (ET) formulas available within the APEX model. One of the major structural differences between NTT and ArcAPEX interfaces is that ArcAPEX uses only the predominant soil for each subarea [37], while NTT assigns a maximum of three soils for every subarea, representing the most predominant soils in the area of interest [38]. Because model computation time takes place at the subarea level, this implies that a model built using NTT will require as much as three times the computation time to complete as one built by the ArcAPEX interface. However, one would hypothesize that although a model built using NTT requires more computation time, it should result in more realistic model outcomes because three soils for each subarea capture the variability better relative to the single soil used in ArcAPEX. However, none of the reported APEX literature presents the impact of the interface used on model outcomes. Therefore, the objectives of this study were to: 1) compare structure and input values of the ArcAPEX and NTT interfaces, and 2) determine the impact of the differences on simulated hydrology and water quality outputs, computation time, parameter sensitivity, and calibration performance.

\section{Methods}

\subsection{Interface Input Structure}

ArcAPEX is an ArcGIS-based user interface that incorporates soil data, topographic, land use, and a built-in APEX-Parameters database to simulate hydrologic and agricultural processes over a field to basin scale drainage area [32]. The NTT interface was developed to enable assessment of impacts of management practices and to facilitate water quality trading. It is a web-based interface with linkage to the APEX model [35].

The main APEX input files are CONTROL, PARM, Soils, and several management files (for operations, fertilizer, grazing, etc.). CONTROL and PARM files contain global parameters, meaning that these parameters are general and contain many coefficients used in different equations and the miscellaneous pa- 
rameters used. The values of these parameters can be adjusted based on the crops, soils, and management practices representing the farming systems found in different regions of US [35] [38]. While the ArcAPEX and NTT interfaces utilize similar input files, there is a major structural difference with respect to the soil databases. Differences in soil databases include how soil properties are organized by layers for APEX and, more significantly, the number of soils for each subarea/or area of interest. In ArcAPEX, only the predominant soil is used for each subarea [37]. A dominant soil is assigned to each subarea from the list of soils in the study area (listed in the SOILCOM.DAT file). A file named filename.sol is used to describe each soil. The NTT interface allows users to verify, modify or delete soils copied from the SSURGO soil database and add or edit layers for the particular field selected in the field's page. The NTT assigns a maximum of three soils for every subarea, representing the most predominant soils in the area of interest [38].

\subsection{Interface Input Values}

The values of the parameters in the Control, Parameter, and Soil files for the respective interfaces were determined after the model was built (see details below). Model building includes study area description, data sources, and model setup.

\subsubsection{Study Area}

Nelson et al. [29] provide a detailed description of the study area; thus only a summary is provided here. Rock Creek, located in northern Ohio, is a third order tributary of the Sandusky River (Figure 1), which flows north through the middle of Seneca County and drains into Lake Erie through Sandusky Bay [39] [40] [41].

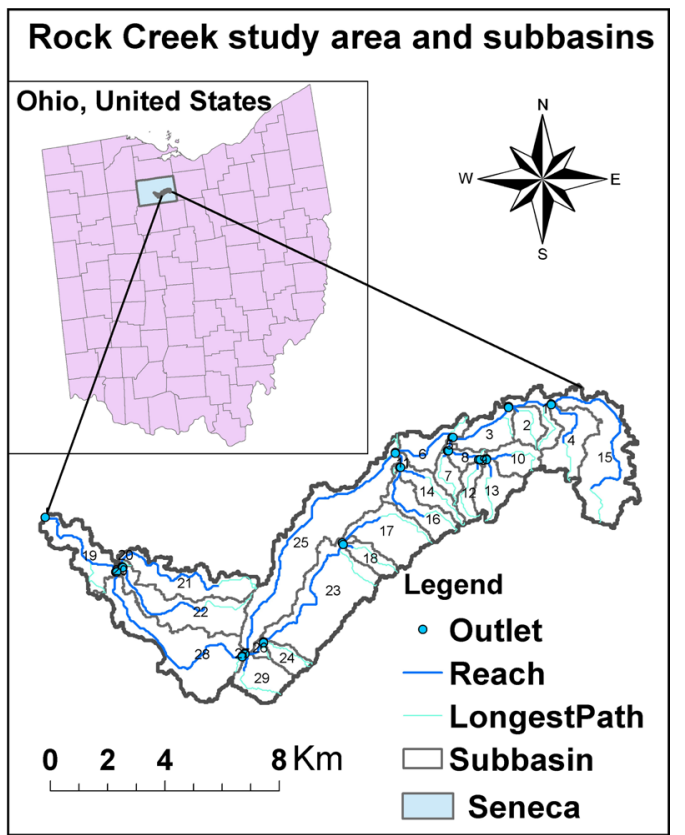

Figure 1. APEX-defined subareas for Rock Creek watershed in northern Ohio. 
Rock Creek watershed is approximately 7500 ha and has nineteen identified soil series, primarily from the Blount-Pewamo-Glynwood soil group [42]. These soils are moderately well drained to very poorly drained, and are located on slopes of $0 \%-7 \%$. Tile drainage occurs in $\sim 90 \%$ of the agricultural fields, primarily in areas with $3 \%$ or less slope. The depth of tile drainage is approximately $0.9 \mathrm{~m}[43]$.

Seneca County's climate is typical of the temperate mid-continent region. Rock Creek watershed is comprised of about $82 \%$ agricultural land, $13 \%$ forest land, and $6 \%$ urban land. Of the croplands, $50 \%$ are soybean, $30 \%$ are corn, and $20 \%$ are wheat [42]. Corn-soybean and corn-soybean-wheat are the most common crop rotations.

\subsubsection{Data Sources}

Three GIS data layers are required for the APEX model: digital elevation model (DEM), soils, and land use data. Sub-area parameters such as slope and slope length were calculated using a 30-m DEM obtained from the USGS

(http://viewer.nationalmap.gov/launch/). The same DEM was used to define the stream network. The parameters required for simulating streamflow, as well as performing sediment yield using the MUSLE soil erodibility $\mathrm{K}$ factor, were parameterized within each interface using the Soil Survey Geographic (SSURGO; http://websoilsurvey.nrcs.usda.gov). Streamflow simulation required soil chemical, physical, and hydraulic model inputs, including maximum rooting depth, soil hydrologic group, moist bulk density, soil profile depth, saturated hydraulic conductivity, available water capacity of the soil layer, and soil texture data (\% clay, sand, silt, and rock fragment content) (Figure 2). Surveys and reports on the study area were used to obtain land use and land cover information as well as

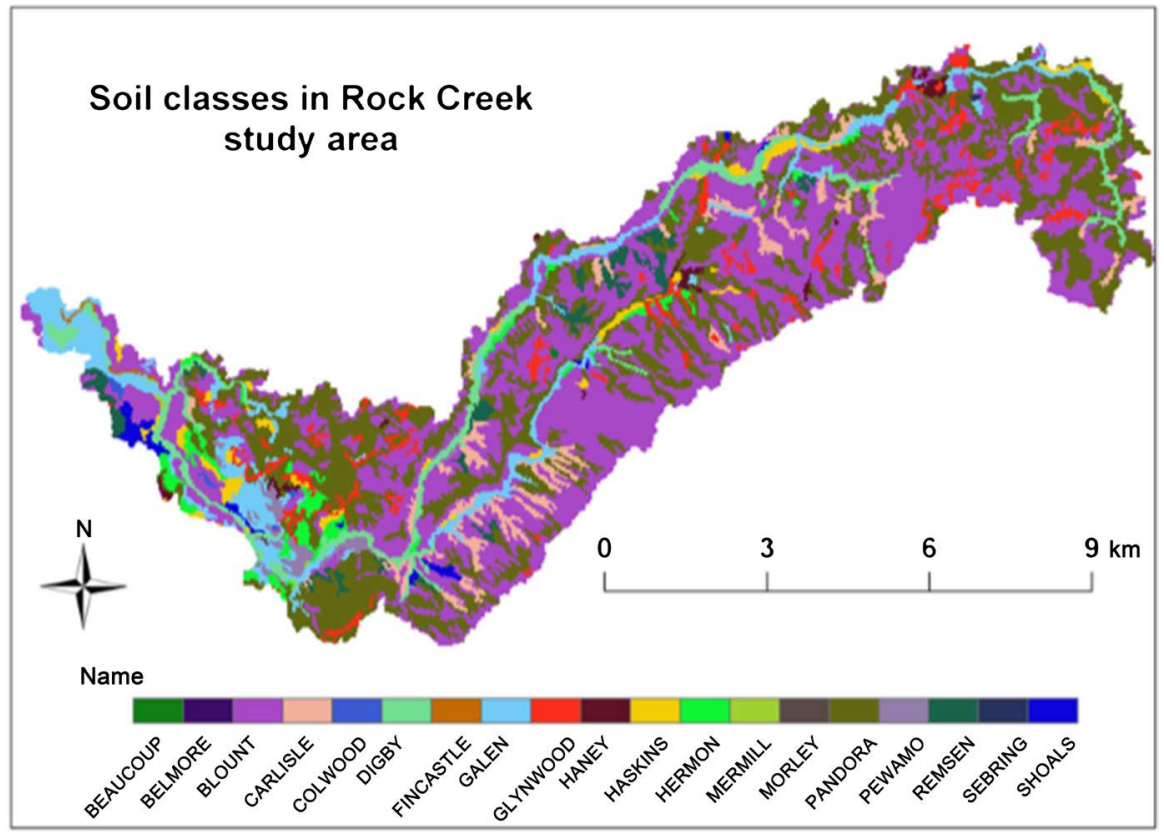

Figure 2. SSURGO soil map for rock creek, Ohio. 
general land management data, including tillage types and dates, planting, fertilization, and harvests for most fields [unpublished data, Heidelberg University; [28] [29]]. Daily weather data (e.g. minimum and maximum temperature, and rainfall) were obtained from the PRISM Climate Group, Oregon State University [44].

The USGS monitors water quality at the outlet of Rock Creek, $0.8 \mathrm{~km}(0.5 \mathrm{mi})$ from the confluence with the Sandusky River (USGS station 04197170) as part of the Heidelberg Tributary Loading Program (HTLP). The station has been in operation since 1982 [45] and is described in detail in Nelson et al. [28]. Since the two interfaces calculated slightly different areas for the watershed, the observed values were adjusted according to each interface's calculation of watershed area (7576.54 ha for ArcAPEX and 7560.85 ha for NTT).

The APEX model was constrained with soft data, including the assurance that simulated values were within $15 \%$ of the average annual evapotranspiration (ET) and tile drainage (QDR) values of $524 \mathrm{~mm} \mathrm{[46]} \mathrm{and} 283 \mathrm{~mm}$ [43], respectively. Soft data are information on processes within a budget that may not be directly measured, including those found in literature, such as annual evapotranspiration (ET), tile drainage, crop yields, or certain species of nutrients [47]. The annual average yield $\pm 35 \%$ for corn, winter wheat, and soybeans was used to constrain crop yield data, which were taken from the Ohio Agricultural Statistics 2015 Annual Bulletin and 2009 Ohio Agricultural Statistics reports [48] [49].

\subsubsection{Model Setup}

The APEX model version 0806 [37] [50] was used in this study. It is important to note that although the NTT interface states that it uses APEX 0806, the executable has been modified. However, the modifications are not documented. ArcAPEX and NTT interfaces were each used to build one project. The APEX project was built (delineated) into subareas along with the corresponding stream network using ArcAPEX [32]. The subarea, APEX's smallest modeling unit, is a function of land use and soil type. An area upstream and contiguous to the outlet at which the flow measurements were made was delineated using the automatic subarea delineation feature on the DEM. The land use, soils, and slope definition tool was used to define the categories appropriately. Using management and land use data collected by study area personnel [51] to define the subareas for creating files resulted in delineation of 29 subareas (Figure 1).

Because NTT cannot currently delineate subareas, the shapefile from the ArcAPEX delineation was used to build an APEX project with the NTT interface [35] [36]. Data on land use and management practices were populated using the NTT interface subsequent to delineation and selection of soil and weather data inputs. Management operations included, but were not limited to, crop type, tillage method, planting date, fertilizer type and amount, irrigation type and amount, harvest date. Operations were the same as those entered in the ArcAPEX interface. Subareas were manually routed using the routing scheme adopted from ArcAPEX. 
The model was run after creation of all subarea files, creating a default model folder for each interface. The model folder includes all necessary input, control, and executable files along with the output files. The parameterization process was then used to edit and update input and control files. The drainage code (IDR) was set to $900 \mathrm{~mm} \mathrm{[43]} \mathrm{to} \mathrm{assign} \mathrm{tile} \mathrm{drainage} \mathrm{to} \mathrm{subareas} \mathrm{with} \mathrm{predomi-}$ nantly crop coverage and slopes $<3 \%$ [52]. The Hargreaves [53] method was used to estimate ET in both interfaces.

\subsection{Model Evaluation}

\subsubsection{Sensitivity Analysis}

Important model parameters for calibration were identified by performing a global sensitivity analysis (GSA) [54] that used variance-based sensitivity analysis to quantify the contribution of change in model parameters to the change in model outputs. The GSA also provided a flexible water simulation platform for incorporating different sets of model parameters. A GSA was implemented using the APEXSENSUN software [27] which is designed for Monte Carlo-based uncertainty analysis [55]. Defaults assigned by the respective interfaces were not altered for parameters that were not being tested for sensitivity.

Forty-two parameters related to nutrients and streamflow (and defined in [37]) were tested through 20,000 simulations (i.e. 20,000 parameter combinations) for sensitivity. The standardized regression coefficient (SRC) was used as a GSA metric for streamflow, total phosphorus (TP), and total nitrogen (TN) predictions in the APEX model. Parameters in which SRC $>0.05$ were considered sensitive. The sensitivity of parameters with an SRC $>0.05$ for streamflow, TN, and TP simulation was determined based on the percentage bias [PBIAS]; [56] and Nash-Sutcliffe efficiency [NSE]; [57] performance measures. Sensitive parameters based on either NSE or PBIAS were selected and used during model calibration and validation. The equations for all simulated components are described in detail in the APEX model theoretical documentation (30).

\subsubsection{Calibration and Model Evaluation}

Previous [58] [59] and current literature review found that most studies used only statistical performance measures to determine adequate calibration and validation. While Wang et al. [60] recommends that modelers obtain a correct water balance that includes all hydrologic components (e.g. surface flow, subsurface flow, percolation, evapotranspiration) and crop yields, with crop yields as the absolute minimum criteria level if no measured water quantity data are available, few of the ensuing peer reviewed papers follow this recommendation rigorously. According to Nelson et al. [29], it is important to utilize the soft data to obtain realistic simulations of various management practices, thus ensuring one gets the right answers for the right reasons [61]. In this study, model performance was assessed using the NSE and PBIAS statistical performance measures calculated with APEXSENSUN [27]. The criteria thresholds for NSE and PBIAS used in this study were the same as those used by Nelson et al. [29]. Moriasi et al. [62] 
considered a model to be calibrated for streamflow if the NSE $\geq 0.50$ and PBIAS $\leq \pm 15 \%$, and for $\mathrm{N}$ and $\mathrm{P}$ if the NSE $\geq 0.35$ and PBIAS $< \pm 30 \%$. In addition, the model was constrained during calibration using soft data [47] value ranges for ET, QDR, and crop yields described earlier. Long-term crop yield ranges (soft data) used to bound the parameter values for corn, wheat, and soybean were 8.6 ton $\mathrm{ha}^{-1} \pm 35 \%, 4.0$ ton $\mathrm{ha}^{-1} \pm 35 \%$, and 2.9 ton $\mathrm{ha}^{-1} \pm 35 \%$, respectively [48] [49]. The statistical performance measures and the soft data constraints together are referred to as performance criteria throughout the rest of this paper. Comparisons on model simulation performance were made for each individual criterion. According to Nelson et al. [29], models evaluated on a daily time step did not meet the selected criteria when simulating daily streamflow. This could be attributed to the precipitation and streamflow measurement cutoff at midnight for each day and the lag time between a precipitation event and a streamflow surge. In a study to determine the impact of length of the calibration period on model performance, Nelson et al. [28] found that the model performed best at an annual temporal scale when using long term (25 years) data to calibrate the model. This study was performed in the same study area with the same 25 years of measured data. Therefore, model performance was evaluated at an annual time step.

\section{Results and Discussion}

\subsection{Impact of Interfaces on Input Values}

\subsubsection{Soils Input Files}

The ArcAPEX interface soil database has four soil types for the study area, which include Pandora, Galen, Digby, and Blount, while the NTT database has three soils. These include "Blount silt loam end moraine 0 to 2 percent slopes", "Blount silt loam end moraine 2 to 4 percent slopes", and "Blount silt loam ground moraine 2 to 4 percent slopes”. ArcAPEX assigns one soil per subarea and creates one soil file per soil type, whereas NTT builds three soil files for each subarea, leading to four soil files for ArcAPEX and 87 soil files for NTT. While both file structures include values for the 19 soil parameters, the ArcAPEX file includes an additional 23 lines of zeros in its formatting, perhaps due to programming. The number of columns beginning at Line 4 indicates the number of soil layers in each soil type, which show a key difference between the ArcAPEX and NTT interfaces and the SSURGO database. Three of the four ArcAPEX soil files had four soil layers, while one type (Pandora) had three. According to the SSURGO database, Pandora has 3 layers, Galen has 3 layers, Digby has 5 layers, and Blount has 4 layers. Each of the three NTT soil files had five soil layers.

Table 1 depicts a comparison of the soil input file values derived from the SSURGO database by ArcAPEX and NTT interfaces, as well as the values from the SSURGO database. Despite both the ArcAPEX and NTT interfaces stating that they use the SSURGO database as their source for soils data, neither match all the values found directly in the SSURGO database. For example, for the organic carbon 


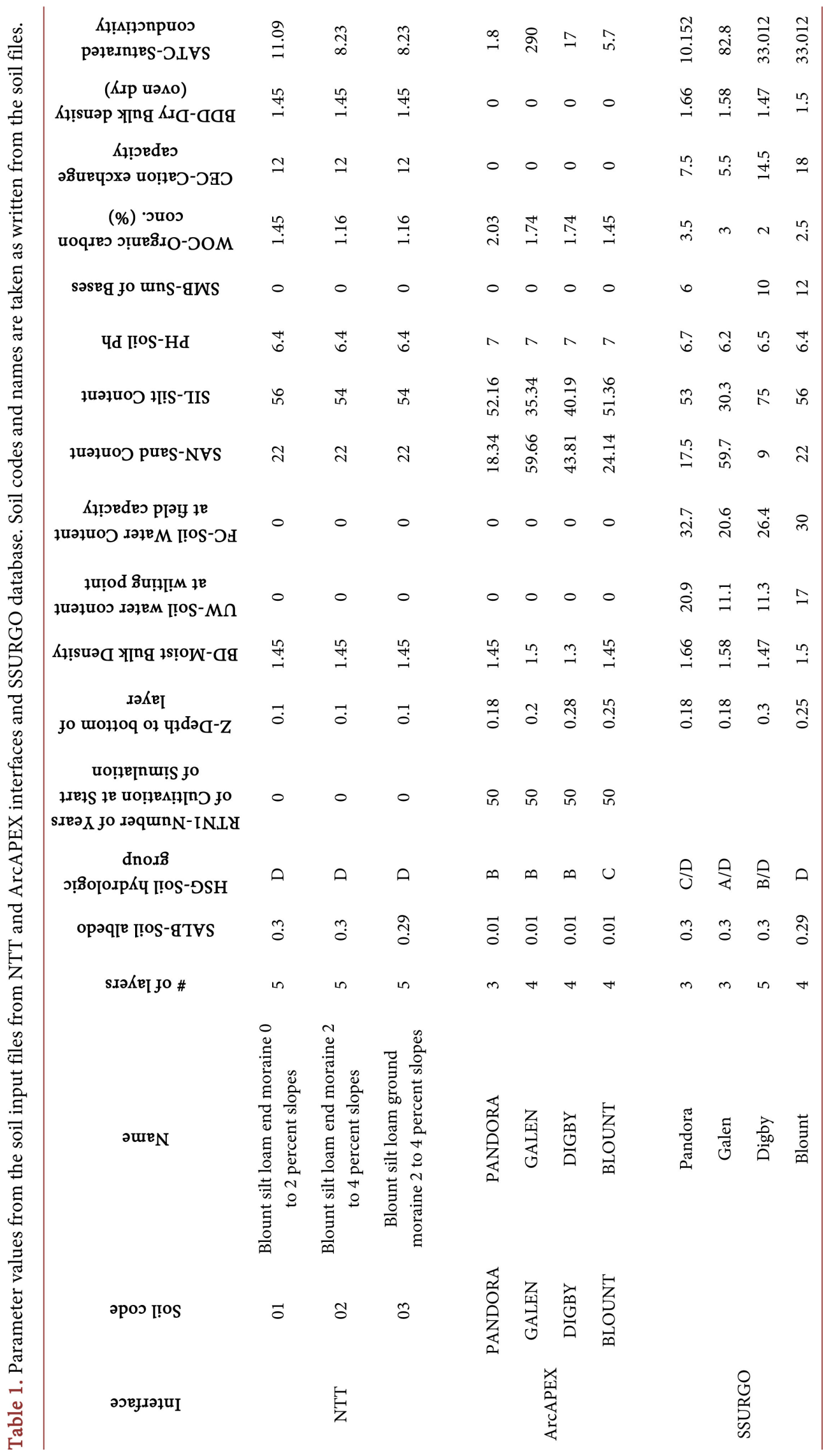


concentration, ArcAPEX ranged from $1.45 \%$ to $2.03 \%$, while NTT ranged from $1.16 \%$ to $1.45 \%$, and SSURGO ranged from $2 \%$ to $3.5 \%$. For texture, NTT used a sand content of $22 \%$ for all three soil types, while ArcAPEX sand content ranged from $18 \%$ for Pandora to $60 \%$ for Galen and SSURGO ranged from $9 \%$ for Digby to $60 \%$ for Galen. While it is acceptable for the values to be different from the SSURGO database, there is no documentation explaining the rationale for the modifications from the original source. This is one of the examples that highlights lack of detailed documentation that would be useful to model users. Saraswat et al. [63] recommend that "modifications, simplifications, or'data cleaning' procedures used in preparing the input data, including any assumptions made to acquire or process ... data to make it compatible" be clearly documented. Such documentation is essential because these values affect different processes. For example, soil texture affects infiltration and soil water holding capacity [64] [65], as well as susceptibility of erosion [66], which in turn, affect ET, drainage, and nutrients.

Other parameters that affect the hydrologic processes include the soil water content values at "wilting point" (at $1500 \mathrm{KPa}$ or -15 bars $(\mathrm{m} / \mathrm{m})$ ) and "field capacity" (at $33 \mathrm{KPa}$ or $-1 / 3$ bars $(\mathrm{m} / \mathrm{m})$ ). While the SSURGO database has values for these parameters, both NTT and ArcAPEX provided a zero in their place. According to the APEX manual, zero is to be entered as a default integer when the value is unknown [37]. However, the zero entered does not represent a value of zero. Rather, the model takes the midpoint of the range given in the manual and utilizes that median as the value in pertinent calculations or functions. For example, for the soil water content at field capacity, the model will use 0.35 , the median value of the default range of $0.1-0.6$. The soil water content levels at the different pressures affect infiltration rates, and therefore calculations of runoff, drainage, and streamflow.

\subsubsection{CONTROL Input Parameters}

There are 77 Control input file parameters, most of which are held constant for all model runs, but only some of them are presented in Table S1. In this study, only parameters related to the equations used, the processes simulated, and where the parameter values were different between interfaces are presented. The notes column in Table S1 provides more information about the parameters. However, there was no description for some of the parameters either in the manual [37] or the theoretical documentation [30]. As noted from Table S1, there are major differences in the default values used by each interface. Parameters such as Return Flow/(Return Flow + Deep Percolation) (RFPO) and Number of years of cultivation at start of simulation (RTN0) directly impact hydrologic processes and nutrient availability. As discussed above, there is no detailed documentation explaining how these default parameter values were determined.

\subsubsection{PARM Input Parameters}

There are 98 Parameter (Parm) input file parameters that consist of mainly equ- 
ation coefficients, but only parameters where values were different between interfaces are presented in Table S2. Lines 1 - 30 of the Parameter file consist of two fields with one S-curve pair per line. Three of these parameters (Aeration stress-root growth, which affects crop yields and ET values; the snowmelt function, which affects tile drainage and ET; and the plant water stress factor which is based on soil water content and affects ET and crop yields) have different values between NTT and ArcAPEX. Other parameters that may impact on water availability include: Reduces NRCS runoff $\mathrm{CN}$ retention parameter for frozen soil, Water stress weighting coefficient, Hydrograph development parameter, Estimates drainage system lateral hydraulic conductivity, Water table recession coefficient, Limits daily water table movement, Water table recession, Subsurface flow factor, and Flood evaporation limit parameters. Sediment routing travel time coefficient and Partitions nitrogen flow from groundwater are examples of parameters that affect nutrient movement. The two parameters relating to pest damage (Pest damage moisture threshold and Pest damage cover threshold) may impact crop yields and ET.

\subsection{Impact of Different Input Values}

\subsubsection{Default Model Simulations}

The results of the comparisons between observed and simulated outputs for the two interfaces are presented in Table 2. The average area was used to compute the observed values used for comparison. Both ArcAPEX and NTT simulated streamflow and tile drainage within 30\%. However, there were major differences in simulated ET with ArcAPEX overpredicting ET by 15\%, while NTT underpredicted by $56 \%$. In general, NTT simulated nutrients and crop yields better than ArcAPEX, with crop yield errors ranging from 13\% - 35\% for NTT and 37\% - 69\% for ArcAPEX (Table 2). While NTT simulated total phosphorus better than ArcAPEX, it should be noted that the ratios of the components that form total $\mathrm{P}$ (the summation of $\mathrm{YP}=$ phosphorus loss in sediment, $\mathrm{QP}=$ phosphorus loss in surface runoff, QDRP = phosphorus loss in drainage, and QRFP = phosphorus loss in quick return flow) are vastly different (Table 3 ). For example, $4 \%$ of TP comes from tile drainage for NTT and $60 \%$ for ArcAPEX. King et al. [43] reported that tile drainage accounted for $40 \%$ of the total $\mathrm{P}$ exported from the watershed.

The differences in simulated total nitrogen could be explained by the soil properties and the Number of years of cultivation at start of simulation (RTN0) parameter (Table S1). ArcAPEX has soils listed as hydrologic group B with high sand content, which have higher infiltration rates than the NTT soils, which are listed as hydrologic group D with higher clay content (Table 1). This can lead to higher nitrogen leaching for ArcAPEX soils, which explains the much higher simulated total nitrogen compared to measured data and NTT simulated values. The RTN0 parameter is set at 150 years for ArcAPEX and 10 for NTT (Table S1). This parameter affects the partitioning of nitrogen and carbon into the passive and slow humus pools. The number of years of cultivation before the simulation starts 
Table 2. The average annual values using the default ArcAPEX and NTT parameter values. Evapotranspiration (ET), Drainage (QDR).

\begin{tabular}{cccccc}
\hline \multirow{2}{*}{ Components } & Measured & \multicolumn{2}{c}{ Simulated } & \% difference from the measured mean \\
\cline { 3 - 6 } & & ArcAPEX & NTT & ArcAPEX & NTT \\
\hline Streamflow (mm) & 368 & 318 & 325 & -14 & -12 \\
ET (mm) & 524 & 603 & 233 & 15 & -56 \\
QDR (mm) & 283 & 202 & 206 & -29 & -27 \\
Total Nitrogen (kg/ha) & 42.9 & 74.9 & 27.6 & 75 & -36 \\
Total Phosphorus (kg/ha) & 4.8 & 1.3 & 2.1 & -73 & -56 \\
Corn (tn/ha) & 8.6 & 5.4 & 9.7 & -37 & 13 \\
Wheat (tn/ha) & 4.0 & 1.3 & 2.6 & -69 & -35 \\
Soy (tn/ha) & 2.9 & 1.3 & 2.5 & -57 & -15 \\
\hline
\end{tabular}

Table 3. Annual averages for total phosphorus (TP) and nitrogen (TN) in $\mathrm{kg} / \mathrm{ha}$. YP = phosphorus loss in sediment, QP = phosphorus loss in surface runoff, QDRP = phosphorus loss in drainage, $\mathrm{QRFP}=$ phosphorus loss in quick return flow, $\mathrm{YN}=$ nitrogen loss in sediment, $\mathrm{QN}=$ nitrogen loss in surface runoff, QDRN = nitrogen loss in drainage, QRFN = nitrogen loss in quick return flow, RSFN = nitrogen yield in return flow, SSFN = nitrogen loss in lateral subsurface flow.

\begin{tabular}{ccccc}
\hline Components & ArcAPEX & \% of total & NTT & \% of total \\
\hline YP & 0.20 & 15.1 & 1.52 & 71.4 \\
QP & 0.33 & 25.4 & 0.52 & 24.3 \\
QDRP & 0.78 & 59.5 & 0.09 & 4.4 \\
QRFP & 0.00 & 0.0 & 0.00 & 0.0 \\
TP & 1.30 & & 2.13 & \\
YN & 1.27 & 1.7 & 6.05 & 21.9 \\
QN & 8.72 & 11.6 & 12.16 & 44.0 \\
QDRN & 64.70 & 86.3 & 9.18 & 33.3 \\
QRFN & 0.05 & 0.1 & 0.01 & 0.0 \\
RSFN & 0.20 & 0.3 & 0.20 & 0.7 \\
SSFN & 0.00 & 0.0 & 0.00 & 0.0 \\
TN & 74.94 & & 27.59 & \\
\hline
\end{tabular}

is used to estimate the fraction of the organic $\mathrm{N}$ pool that is mineralizable. Mineralization is more rapid from soil recently in sod. Also increasing the number of years the field has been in cultivation increases the amount of $\mathrm{C}$ and $\mathrm{N}$ in the passive pool. This means it will take longer for the carbon and nitrogen to become available. The increased levels of nitrogen leaching and unavailability of nitrogen from the organic pool as indicated by the number of years of cultivation at the start of simulation parameter may be the reason the crop yields are so much lower in the ArcAPEX simulations. 
The comparison of simulated ET and crop yield results highlight a potential issue. For NTT to have simulated crop yields better than ArcAPEX while predicting ET so poorly, and vice versa, indicates that there is a disconnect between ET and crop yields within the model. In addition, the streamflow, drainage, and surface runoff were comparable between ArcAPEX and NTT while simulated ET values were quite different, raising the question of where that missing water in the water budget is going. These differences in the outputs from the default values from the two interfaces lead us to provide two recommendations. Model developers need to take a look at the interactions between water, nitrogen, and crop growth routines, while model users need to pay attention to the soils and control parameter values prior to beginning sensitivity analyses and the calibration process that mainly focuses on the PARM file parameters.

\subsubsection{Computation Times}

To run the 20,000 model simulations for calibration and sensitivity analysis, the computation time for the ArcAPEX was just over 6 days, while the NTT interface took just under 17 days (Figure 3). As discussed above, this is attributed to the utilization of three soil types per hydrologic subunit for NTT, whereas ArcAPEX only assigns one.

\subsubsection{Sensitivity Analysis}

The rankings of the parameters found to be most sensitive for the two interfaces using NSE and PBIAS are shown in Table 4. The same 12 parameters were found to be most sensitive for streamflow, total nitrogen (TN), and total phosphorus (TP) for the ArcAPEX and NTT interfaces. The rankings for the Root growth soil parameter had the same ranking for both the ArcAPEX and NTT interfaces for streamflow and TP (NSE and PBIAS), and the Soil evaporation-plant cover parameter had the same top ranking for streamflow (NSE and PBIAS) and third ranking for TN (PBIAS only).

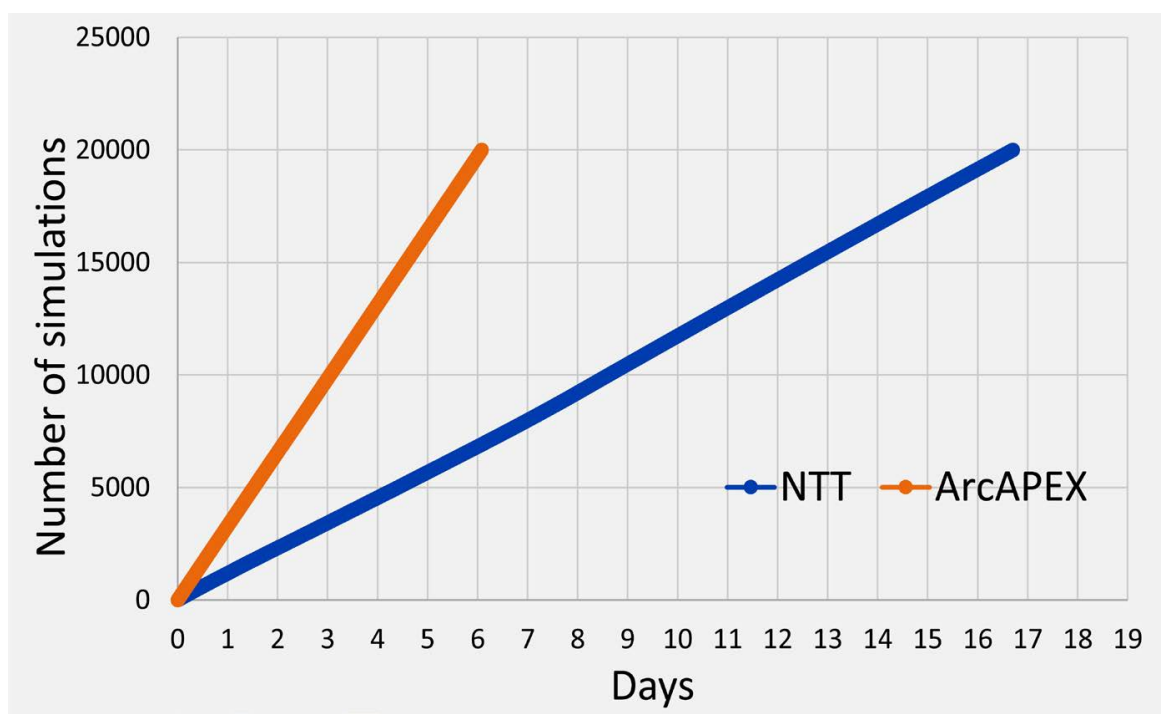

Figure 3. Computation times for the ArcAPEX and NTT interfaces for 20,000 runs. 
Table 4. Sensitive parameters and their respective ranking based on PBIAS and NSE performance evaluation measures for the ArcAPEX and NTT interfaces. APEX PARM file parameter numbers in parentheses [20]. NS = Parameter with $<0.05$ SRC. Total nitrogen (TN), total phosphorus (TP).

\begin{tabular}{|c|c|c|c|c|c|c|c|c|c|c|c|c|}
\hline & \multicolumn{6}{|c|}{ ArcAPEX } & \multicolumn{6}{|c|}{ NTT } \\
\hline & \multicolumn{2}{|c|}{ Streamflow } & \multicolumn{2}{|c|}{$\mathrm{TN}$} & \multicolumn{2}{|c|}{$\mathrm{TP}$} & \multicolumn{2}{|c|}{ Streamflow } & \multicolumn{2}{|c|}{$\mathrm{TN}$} & \multicolumn{2}{|c|}{$\mathrm{TP}$} \\
\hline & NSE & PBIAS & NSE & PBIAS & NSE & PBIAS & NSE & PBIAS & NSE & PBIAS & NSE & PBIAS \\
\hline Microbial decay rate coefficient (70) & 7 & 4 & 10 & 5 & 7 & NS & NS & NS & 6 & 1 & NS & 7 \\
\hline $\begin{array}{l}\text { Coefficient adjusts microbial activity function in the } \\
\text { top soil layer (69) }\end{array}$ & 5 & 3 & 9 & NS & 4 & NS & NS & 4 & 4 & 5 & NS & 2 \\
\hline $\mathrm{N}$ fixation $(7)$ & NS & NS & 5 & 2 & NS & NS & NS & NS & 8 & NS & NS & NS \\
\hline Nitrate leaching ratio (14) & NS & NS & 1 & 7 & NS & NS & NS & NS & 2 & 2 & NS & NS \\
\hline Rainfall interception coefficient (50) & 9 & NS & NS & NS & 8 & 6 & 4 & 3 & NS & NS & NS & 9 \\
\hline Root growth-soil strength (2) & 2 & 2 & 8 & 6 & 1 & 1 & 2 & 2 & 3 & NS & 1 & 1 \\
\hline parameter (15) & 3 & NS & 7 & 8 & 9 & NS & 5 & NS & NS & NS & 2 & 5 \\
\hline Runoff curve number initial abstraction (20) & 4 & 5 & 6 & NS & 2 & 3 & 3 & NS & 5 & 4 & 8 & NS \\
\hline RUSLE C-factor coefficient (46) & NS & NS & NS & NS & 6 & 4 & NS & NS & NS & NS & 5 & 3 \\
\hline SCS curve number index coefficient (42) & 6 & NS & NS & NS & 3 & 5 & 6 & NS & NS & NS & 3 & 4 \\
\hline Soil evaporation-plant cover factor (17) & 1 & 1 & 3 & 3 & 10 & NS & 1 & 1 & NS & 3 & 4 & 8 \\
\hline Soluble phosphorus runoff coefficient (8) & NS & NS & NS & NS & 5 & 2 & NS & NS & NS & NS & NS & 6 \\
\hline $\begin{array}{l}\text { Volatilization/nitrification partitioning coefficient } \\
\text { (72) }\end{array}$ & NS & NS & 4 & 1 & NS & NS & NS & NS & 7 & NS & 7 & NS \\
\hline Water storage $\mathrm{N}$ leaching (4) & 8 & NS & 2 & 4 & NS & NS & NS & NS & 1 & NS & 6 & NS \\
\hline
\end{tabular}

\subsubsection{Model Performance}

The number and range of values of simulations that met individual performance criterion are presented in Table 5. For streamflow and drainage, there was little difference between ArcAPEX and NTT. However, ArcAPEX had over 12,500 models meet the criteria for ET, while NTT had zero. For corn and soybeans, NTT had over 16,000 and 14,000 models meet the $\pm 35 \%$ target, while ArcAPEX had over 2600 simulations that met the criteria for corn and zero for soybeans. The ArcAPEX interface had three models that met all of the criteria except those for the wheat and soy crop yield. For the NTT interface, over 5800 models met all of the crop yield criteria, but no model met the criteria for ET. For those NTT simulations that met the nutrient criteria, none met the drainage criteria. This difference in model performance may lead users to choose an interface based on the criteria in which they are most interested. However, as can be noted from the results, none of the simulations from either interface met all of the criteria listed. These results can be explained by the findings from the comparison of the outputs using the default values. Based on those results, it was noted that there is a disconnect between ET and crop yields within the model. Also, the results of no NTT model meeting the ET criteria are in line with the results of the default input parameters where there were indications of issues with the water budgets. 
Table 5. The number of models and range of values that met the established performance model criteria. Evapotranspiration (ET), Drainage (QDR).

\begin{tabular}{ccccccc}
\hline & & \multicolumn{2}{c}{ ArcAPEX } & \multicolumn{2}{c}{ NTT } \\
\hline \multirow{3}{*}{ Streamflow } & NSE & $\geq 0.50$ & 15951 & $0.50-0.73$ & 16,801 & $0.50-0.77$ \\
& PBIAS (\%) & \pm 15 & 8728 & $-15-15$ & 9614 & $-15-15$ \\
Water Budget & ET (mm) & $445-603$ & 12623 & $445-603$ & 0 & NA \\
& QDR (mm) & $241-325$ & 4192 & $241-325$ & 6474 & $241-325$ \\
Total & NSE & $\geq 0.35$ & 18 & $0.35-0.50$ & 0 & NA \\
Nitrogen & PBIAS (\%) & \pm 30 & 230 & $-30-30$ & 8468 & $-30-30$ \\
Total & NSE & $\geq 0.35$ & 1528 & $0.35-0.44$ & 1 & 0.36 \\
Phosphorus & PBIAS (\%) & \pm 30 & 8760 & $-11-30$ & 1789 & $-30-30$ \\
& Corn (tn/ha) & $5.6-11.6$ & 2613 & $5.6-8.6$ & 16,248 & $5.6-10.4$ \\
Crops & Wheat (tn/ha) & $2.6-5.4$ & 10329 & $2.6-5$ & 7197 & $2.6-4.9$ \\
& Soy (tn/ha) & $1.9-3.9$ & 0 & NA & 14264 & $1.9-2.5$ \\
\hline
\end{tabular}

This led us to recommend that the interaction between crop yields, water, and nutrient routines be re-evaluated by the developers, while the users take note of the soils and control parameter values before carrying out sensitivity analyses and model calibration. This indicates more work is needed to ensure models that have proper representation before being used for scenario analysis.

\section{Conclusions}

In this study, the structure and input values of the ArcAPEX and NTT interfaces were compared and the impact of the differences on simulated water quality and quantity outputs, computation time, parameter sensitivity, and calibration performance was determined. There were major differences in the soils, PARM, and CONTROL input values for the two interfaces that affect water budget components, nutrient transport, and crop growth. It was also noted that the soils input parameter values were different from those in the SSURGO database. While it is acceptable for the values to be different from the SSURGO database, there is no documentation explaining the rationale for the modifications from the original source. Overall, there is a lack of detailed documentation on how these default parameter values were determined that would be useful to model users. Such documentation is essential because these values affect different processes.

ArcAPEX uses only the predominant soil for each subarea, while NTT assigns a maximum of three soils for every subarea, representing the most predominant soils in the area of interest. The differences in this structure of the soils input files affected model simulation times, leading to a computation time three times longer for NTT than for ArcAPEX project.

The comparison of simulated ET and crop yield results using the default input parameter values for the two interfaces highlighted a potential issue. For exam- 
ple, NTT simulated crop yields better than ArcAPEX while predicting ET so poorly, and vice versa, indicating a disconnect between ET and crop yields within the APEX model. In addition, the streamflow, drainage, and surface runoff were comparable between ArcAPEX and NTT while simulated ET values were quite different, raising the question of where that missing water in the water budget is going. These differences in the outputs from the default values from the two interfaces lead us to provide two recommendations. Model developers need to take a look at the interactions between water, nitrogen, and crop growth routines, while model users need to pay attention to the soils and control parameter values prior to beginning sensitivity analyses and the calibration process that mainly focuses on the PARM file parameters.

Sensitivity analysis results indicated that twelve sensitive parameters were the same between the two interfaces, though the order of sensitivity was different. Using the sensitive parameters, calibration results showed none of the models met all of the criteria (statistical performance measures, water budget components, and crop yields) for either interface. These results can be explained by the findings from the comparison of the outputs using the default values. Therefore, more work is needed to ensure models that have proper representation before being used for nutrient and land management scenario analysis.

\section{Acknowledgements}

The authors are grateful to all Heidelberg University investigators and staff at the National Center for Water Quality Research who have supported the long term data collection in this watershed. Mention of trade names or commercial products in this publication is solely for the purpose of providing specific information and does not imply recommendation or endorsement by the US Department of Agriculture.

\section{Funding}

Funding for this study was provided by USDA-Office of Environmental Markets. Project Number: 3070-11130-005-10-I.

\section{Conflicts of Interest}

The authors declare no conflicts of interest regarding the publication of this paper.

\section{References}

[1] Mitsch, W.J., Day, J.W., Gilliam, J.W., Groffman, P.M., Hey, D.L., Randall, G.W. and Wang, N. (2001) Reducing Nitrogen Loading to the Gulf of Mexico from the Mississippi River Basin: Strategies to Counter a Persistent Ecological Problem Ecotechnology-The Use of Natural Ecosystems to Solve Environmental Problems-Should Be a Part of Efforts to Shrink the Zone of Hypoxia in the Gulf of Mexico. BioScience, 51, 373-388.

https://doi.org/10.1641/0006-3568(2001)051[0373:RNLTTG]2.0.CO;2 
[2] Moffat, A.S. (1998) Global Nitrogen Overload Problem Grows Critical. Science, 279, 988-989. https://doi.org/10.1126/science.279.5353.988

[3] Robertson, G.P. and Vitousek, P.M. (2009) Nitrogen in Agriculture: Balancing the Cost of an Essential Resource. Annual Review of Environment and Resources, 34, 97-125. https://doi.org/10.1146/annurev.environ.032108.105046

[4] Drewry, J.J., Newham, L.T.H., Greene, R.S.B., Jakeman, A.J. and Croke, B.F.W. (2006) A Review of Nitrogen and Phosphorus Export to Waterways: Context for Catchment Modelling. Marine and Freshwater Research, 57, 757-774. https://doi.org/10.1071/MF05166

[5] Korsaeth, A. (2008) Relations between Nitrogen Leaching and Food Productivity in Organic and Conventional Cropping Systems in a Long-Term Field Study. Agriculture, Ecosystems \& Environment, 127, 177-188.

https://doi.org/10.1016/j.agee.2008.03.014

[6] Arnold, J.G. and Allen, P.M. (1993) A Comprehensive Surface-Ground Water Flow Model. Journal of Hydrology, 142, 47-69.

https://doi.org/10.1016/0022-1694(93)90004-S

[7] Williams, J.R. and Izaurralde, R.C. (2005) The APEX Model. BRC Rep. 2005-02. Blackland Res. Center, Texas A\&M Univ., Temple.

https://doi.org/10.1201/9781420037432.ch18

[8] Cornelissen, T., Diekkrüger, B. and Giertz, S. (2013) A Comparison of Hydrological Models for Assessing the Impact of Land Use and Climate Change on Discharge in a Tropical Catchment. Journal of Hydrology, 498, 221-236.

https://doi.org/10.1016/j.jhydrol.2013.06.016

[9] Tegegne, G., Park, D.K. and Kim, Y.-O. (2017) Comparison of Hydrological Models for the Assessment of Water Resources in a Data-Scarce Region, the Upper Blue Nile River Basin. Journal of Hydrology: Regional Studies, 14, 49-66. https://doi.org/10.1016/j.ejrh.2017.10.002

[10] Douglas-Mankin K.R., Srinivasan, R. and Arnold, J.G. (2010) Soil and Water Assessment Tool (SWAT) Model: Current Developments and Applications. Transactions of the ASABE, 53, 1423-1431. https://doi.org/10.13031/2013.34915

[11] Gassman, P.W., Reyes, M., Green, C.H. and Arnold, J.G. (2007) The Soil and Water Assessment Tool: Historical Development, Applications, and Future Directions. Transactions of the ASABE, 50, 1211-1250. https://doi.org/10.13031/2013.23637

[12] Gassman, P.W., Williams, J.R., Wang, X., Saleh, A., Osei, E., Hauck, L.M., Izaurralde, R.C. and Flowers, J.D. (2010) The Agricultural Policy/Environmental eXtender (APEX) Model: An Emerging Tool for Landscape and Watershed Environmental Analyses. Transactions of the ASABE, 53, 711-740. https://doi.org/10.13031/2013.30078

[13] Geza, M. and McCray, J.E. (2018) Effects of Soil Data Resolution on SWAT Model Stream Flow and Water Quality Predictions. Journal of Environmental Management, 88, 393-406. https://doi.org/10.1016/j.jenvman.2007.03.016

[14] Gatzke, S.E., Beaudette, D.E., Ficklin, D.L., Luo, Y., O'Green, A.T. and Zhang, M. (2011) Aggregation Strategies for SSURGO Data: Effects on SWAT Soil Inputs and Hydrologic Outputs. Soil Science Society of America Journal, 75, 1908-1921. https://doi.org/10.2136/sssaj2010.0418

[15] Monks, A.M. (2016) Comparing Soil Datasets with the APEX Model: Calibration and Validation for Hydrology and Crop Yield in Whatcom County, Washington. Master's Thesis, Western Washington University, Bellingham.

[16] Peschel, J.M., Haan, P.K. and Lacey, R.E. (2006) Influences of Soil Dataset Resolu- 
tion on Hydrologic Modeling. Journal of the American Water Resources Association, 42, 1371-1389. https://doi.org/10.1111/j.1752-1688.2006.tb05307.x

[17] Starks, P. and Moriasi, D. (2009) Spatial Resolution Effect of Precipitation Data on SWAT Calibration and Performance: Implications for CEAP. Transactions of the ASABE, 52, 1171-1180. https://doi.org/10.13031/2013.27792

[18] Glotter, M.J., Moyer, E.J., Ruane, A.C. and Elliot, J.W. (2015) Evaluating the Sensitivity of Agricultural Model Performance to Different Climate Inputs. Journal of Applied Meteorology and Climatology, 55, 579-594. https://doi.org/10.1175/JAMC-D-15-0120.1

[19] Tadesse, H.K., Moriasi, D.N., Gowda, P., Marek, G.W., Steiner, J.L., Brauer, D.K., Talebizadeh, M., Nelson, A.M. and Starks, P.J. (2018) Evaluating Evapotranspiration Estimation Methods in APEX Model for Dryland Cropping Systems in a Semi-Arid Region. Agricultural Water Management, 206, 217-228. https://doi.org/10.1016/j.agwat.2018.04.007

[20] Li, J. and Wong, D.W.S. (2010) Effects of DEM Sources on Hydrologic Applications. Computers, Environment and Urban Systems, 34, 251-261. https://doi.org/10.1016/j.compenvurbsys.2009.11.002

[21] Cho, S.-M. and Lee, M.W. (2001) Sensitivity Considerations When Modeling Hydrologic Processes with Digital Elevation Model. Journal of the American Water Resources Association, 37, 931-934. https://doi.org/10.1111/j.1752-1688.2001.tb05523.x

[22] Bailey, R., Rathjens, H., Bieger, K., Chaubey, I. and Arnold, J. (2017) SWATMOD-PREP: Graphical User Interface for Preparing Coupled SWAT-MODFLOW Simulations. Journal of the American Water Resources Association, 53, 400-410. https://doi.org/10.1111/1752-1688.12502

[23] Garrote, L. and Bras, R.L. (1995) An Integrated Software Environment for Real-Time Use of a Distributed Hydrologic Model. Journal of Hydrology, 167, 307-326. https://doi.org/10.1016/0022-1694(94)02593-Z

[24] Juracek, K.E. and Wolock, D.M. (2002) Spatial and Statistical Differences between 1:250,000- and 1:24,000-Scale Digital Soil Databases. Journal of Soil and Water Conservation, 57, 89-94. https://doi.org/10.2489/jswc.65.2.92

[25] Mednick, A.C. (2010) Does Soil Data Resolution Matter? State Soil Geographic Database versus Soil Survey Geographic Database in Rainfall-Runoff Modeling across Wisconsin. Journal of Soil and Water Conservation, 65, 190-199. https://doi.org/10.2489/jswc.65.3.190

[26] Van Liew, M.W., Wortmann, C.S., Moriasi, D.N., King, K.W., Flanagan, D.C., Veith, T.L., McCarty, G.W., Bosch, D.D. and Tomer, M.D. (2017) Evaluating the APEX Model for Simulating Streamflow and Water Quality on Ten Agricultural Watersheds of the United States. Transactions of the ASABE, 60, 123-146. https://doi.org/10.13031/trans.11903

[27] Talebizadeh, M., Moriasi, D., Steiner, J.S., Gowda, P., Tadesse, H., Nelson, A.M. and Starks, P.J. (2018) APEXSENSUN: An Open-Source Package in R for Sensitivity Analysis and Model Performance Evaluation for the APEX Model. Journal of the American Water Resources Association, 54, 1270-1284. https://doi.org/10.1111/1752-1688.12686

[28] Nelson, A.M., Moriasi, D.N., Talebizadeh, M., Steiner, J.L., Confesor, R.B., Gowda, P.H., Starks, P.J. and Tadesse, H. (2017) Impact of Length of Dataset on Streamflow Calibration Parameters and Performance of APEX Model. Journal of the American Water Resources Association, 53, 1164-1177. 
https://doi.org/10.1111/1752-1688.12564

[29] Nelson, A.M., Moriasi, D.N., Talebizadeh, M., Steiner, J.L., Gowda, P.H., Starks, P.J. and Tadesse, H. (2018) Use of Soft Data for Multi-Criteria Calibration and Validation of APEX: Impact on Model Simulations. Journal of Soil and Water Conservation, 73, 623-636. https://doi.org/10.2489/jswc.73.6.623

[30] Williams, J.R., Izaurralde, R.C. and Steglich, E.M. (2008) Agricultural Policy/Environmental eXtender Model Theoretical Documentation Version 0604. BREC Report \# 2008-17, AgriLife Research, Texas A\&M, Blackland Research and Extension Center, Temple.

http://epicapex.tamu.edu/files/2013/02/the-apex-theoretical-documentation.pdf

[31] Williams, J.R. (1990) The Erosion Productivity Impact Calculator (EPIC) Model: A Case History. Philosophical Transactions of the Royal Society of London, 329, 421-428. https://doi.org/10.1098/rstb.1990.0184

[32] Tuppad, P., Winchell, M.F., Wang, X., Srinivasan, R. and Williams, J.R. (2009) ArcAPEX:ArcGIS Interface for Agricultural Policy Environmental eXtender (APEX) Hydrology/Water Quality Model. International Agricultural Engineering Journal, 18, 59-71.

[33] Siemers, M., Plotkin, S. and Gassman, P. (2014) Interactive APEX (i_APEX) User's Guide to Using APEX2110 and APEX0806. Technical Report 14-TR 50, Iowa State University, Ames, 78.

[34] Steglich, E.M. (2014) WinAPEX: An APEX Window's Interface Users Guide. Blackland Research and Extension Center, Temple.

[35] Saleh, A., Gallego, O., Osei, E., Lal, H., Gross, C., McKinney, S. and Cover, H. (2011) Nutrient Tracking Tool-A User-Friendly Tool for Calculating Nutrient Reductions for Water Quality Trading. Journal of Soil and Water Conservation, 66, 400-410. https://doi.org/10.2489/jswc.66.6.400

[36] Saleh, A., Osei, E. and Gallego, O. (2012) Evaluating Nutrient Tracking Tool (NTT) and Simulated Conservation Practices. 21 st Century Watershed Technology Conference and Workshop, Bari, 27 May-1 June 2012, Paper No. 12-12940, 9 p.

[37] Steglich, E.M. and Williams, J.R. (2013) Agricultural Policy/Environmental eXtender Model Users's Manual: Version 0806. Blackland Research and Extension Center, Temple.

[38] Saleh, A., Selman, M. and Gallego, O. (2018) Nutrient Tracking Tool (NTT): User Manual. Modeling Team at TIAER Tarleton State University, Stephenville. http://ntt.tiaer.tarleton.edu/basic_help.pdf

[39] Ohio Department of Natural Resources (1960) Water Inventory of the Maumee River Basin, Ohio. Division of Water, Ohio Water Plan Inventory, Rpt. No. 11, 112 p.

[40] Ohio Department of Natural Resources (1966) Water Inventory of the Portage River and Sandusky River Basins and Adjacent Lake Erie Tributary Areas. Division of Water, Ohio Water Plan Inventory, Rpt. No. 20, 131 p.

[41] Ohio Department of Natural Resources (1967) The Northwest Ohio Water Development Plan, a Comprehensive Program for All Phases of Water Management. Ohio Water Commission, Burgess \& Niple Ltd., 299 p.

[42] Meals, D.W., Richards, P., Confesor, R., Czajkowski, K., Bonnell, J., Osmond, D.L., Hoag, D.L.K., Spooner, J. and McFarland, M.L. (2012) Rock Creek Watershed, Ohio: National Institute of Food and Agriculture-Conservation Effects Assessment Project. In: Osmond, D.L., Meals, D.W., Hoag, D. and Arabi, M., Eds., How to Build Better Agricultural Conservation Programs to Protect Water Quality. The National 
Institute of Food and Agriculture-Conservation Effects Assessment Project Experience, Soil and Water Conservation Society, Ankeny, 316-326.

[43] King, K.W., Fausey, N.R. and Williams, M.R. (2014) Effect of Subsurface Drainage on Streamflow in an Agricultural Headwater Watershed. Journal of Hydrology, 519, 438-445. https://doi.org/10.1016/j.jhydrol.2014.07.035

[44] PRISM Climate Group, Oregon State University (2015). http://www.prism.oregonstate.edu

[45] Baker, D.B., Confesor, R., Ewing, D.E., Johnson, L.T., Kramer, J.W. and Merryfield, B.J. (2014) Phosphorus Loading to Lake Erie from the Maumee, Sandusky and Cuyahoga Rivers: The Importance of Bioavailability. Journal of Great Lakes Research, 40, 502-517. https://doi.org/10.1016/j.jglr.2014.05.001

[46] Bjorneberg, D.L. and King, K. (2012) Water Balance for a West and Midwest Watershed. ASABE Annual International Meeting Proceedings, Dallas, 29 July 2012, Paper No. 12-1337056, 1-11.

[47] Arnold, J.G., Youssef, M.A., Yen, H., White, M.J., Sheshukov, A.Y., Sadeghi, A.M., Moriasi, D.M., Steiner, J.L., Amatya, D.M., Skaggs, R.W., Haney, E.B., Jeong, J., Arabi, M. and Gowda, P.H. (2015) Hydrological Processes and Model Representation: Impact of Soft Data on Calibration. Transactions of the ASABE, 58, 1637-1660. https://doi.org/10.13031/trans.58.10726

[48] USDA: National Agricultural Statistics Service (2015) Ohio Agricultural Statistics 2015 Annual Bulletin. 17-18.

[49] Ohio Department of Agriculture (2009) 2009 Ohio Agricultural Statistics. 41-42.

[50] Williams, J.R., Izaurralde, R.C. and Steglich, E.M. (2012) Agricultural Policy/Environmental eXtender Model Theoretical Documentation Version 0806. Texas A\&M AgriLife Blackland Research and Extension Center, Temple.

http://epicapex.tamu.edu/files/2014/10/APEX0806-theoretical-documentation.pdf

[51] Confessor, R. (2015) Personal Communication, 8 October 2015. Heidelberg University, Tiffin.

[52] Confessor, R. (2016) Personal Communication, 13 January 2016. Heidelberg University, Tiffin.

[53] Hargreaves, G.H. and Samani, Z.A. (1985) Reference Crop Evapotranspiration from Temperature. Applied Engineering in Agriculture, 1, 96-99. https://doi.org/10.13031/2013.26773

[54] Yuan, Y., Khare, Y., Wang, X., Parajuli, P.B., Kisekka, I. and Finsterle, S. (2015) Hydrological and Water Quality Models: Sensitivity. Transactions of the ASABE, 58, 1721-1744. https://doi.org/10.13031/trans.58.10611

[55] Saltelli, A., Tarantola, S., Campolongo, F. and Ratto, M. (2004) Sensitivity Analysis in Practice: A Guide to Assessing Scientific Models. John Wiley and Sons, Chichester, 218.

[56] Gupta, H.V., Sorooshian, S. and Yapo, P.O. (1999) Status of Automatic Calibration for Hydrologic Models: Comparison with Multilevel Expert Calibration. Journal of Hydrology, 4, 135-143. https://doi.org/10.1061/(ASCE)1084-0699(1999)4:2(135)

[57] Nash, J.E. and Sutcliffe, J.V. (1970) River Flow Forecasting through Conceptual Models, Part 1-A Discussion of Principles. Journal of Hydrology, 10, 282-290. https://doi.org/10.1016/0022-1694(70)90255-6

[58] Moriasi, D.N., Arnold, J.G., Van Liew, M.W., Bingner, R.L., Harmel, R.D. and Veith, T.L. (2007) Model Evaluation Guidelines for Systematic Quantification of Accuracy in Watershed Simulations. Transactions of the ASABE, 50, 885-900. 
https://doi.org/10.13031/2013.23153

[59] Moriasi, D.N., King, K.W., Bosch, D.D., Bjorneberg, D.L., Teet, S., Guzman, J.A. and Williams, M.R. (2016) Framework to Parameterize and Validate APEX to Support Deployment of the Nutrient Tracking Tool. Agricultural Water Management, 177, 146-164. https://doi.org/10.1016/j.agwat.2016.07.009

[60] Wang, X., Williams, J.R., Gassman, P.W., Baffaut, C., Izaurralde, R.C., Jeong, J. and Kiniry, J.R. (2012) EPIC and APEX: Model Use, Calibration, and Validation. Transactions of the ASABE, 55, 1447-1462. https://doi.org/10.13031/2013.42253

[61] Kirchner, J.W. (2006) Getting the Right Answers for the Right Reasons: Linking Measurements, Analyses, and Models to Advance the Science of Hydrology. Water Resources Research, 42, W03S04. https://doi.org/10.1029/2005WR004362

[62] Moriasi, D.N., Gitau, M.W., Pai, N. and Daggupati, P. (2015) Hydrologic and Water Quality Models: Performance Measures and Criteria. Transactions of the ASABE, 58, 1763-1785. https://doi.org/10.13031/trans.58.10715

[63] Saraswat, D., Frankenberg, J.R., Pai, N., Ale, S., Daggupati, P., Douglas-Mankin, K.R. and Youssef, M.A. (2015) Hydrologic and Water Quality Models: Documentation and Reporting Procedures for Calibration, Validation, and Use. Transactions of the ASABE, 58, 1787-1797. https://doi.org/10.13031/trans.58.10707

[64] Saxton, K.E. and Rawls, W.J. (2006) Soil Water Characteristic Estimates by Texture and Organic Matter for Hydrologic Solutions. Soil Science Society of America Journal, 70, 1569-1578. https://doi.org/10.2136/sssaj2005.0117

[65] Wang, T., Istanbulluoglu, E., Lenters, J. and Scott, D. (2009) On the Role of Groundwater and Soil Texture in the Regional Water Balance: An Investigation of the Nebraska Sand Hills, USA. Water Resources Research, 45, W10413. https://doi.org/10.1029/2009WR007733

[66] Easton, Z.M. and Bock, E. (2016) Soil and Soil Water Relationships. Virginia Cooperative Extension, Virginia State University, Petersburg, Publication BSE-194P, 9. 


\section{Supplementary Materials}

Table S1: Parameter values from the Control input file from NTT and ArcAPEX interfaces, Table S2:

Parameter values from the Parameter input files from NTT and ArcAPEX interfaces.

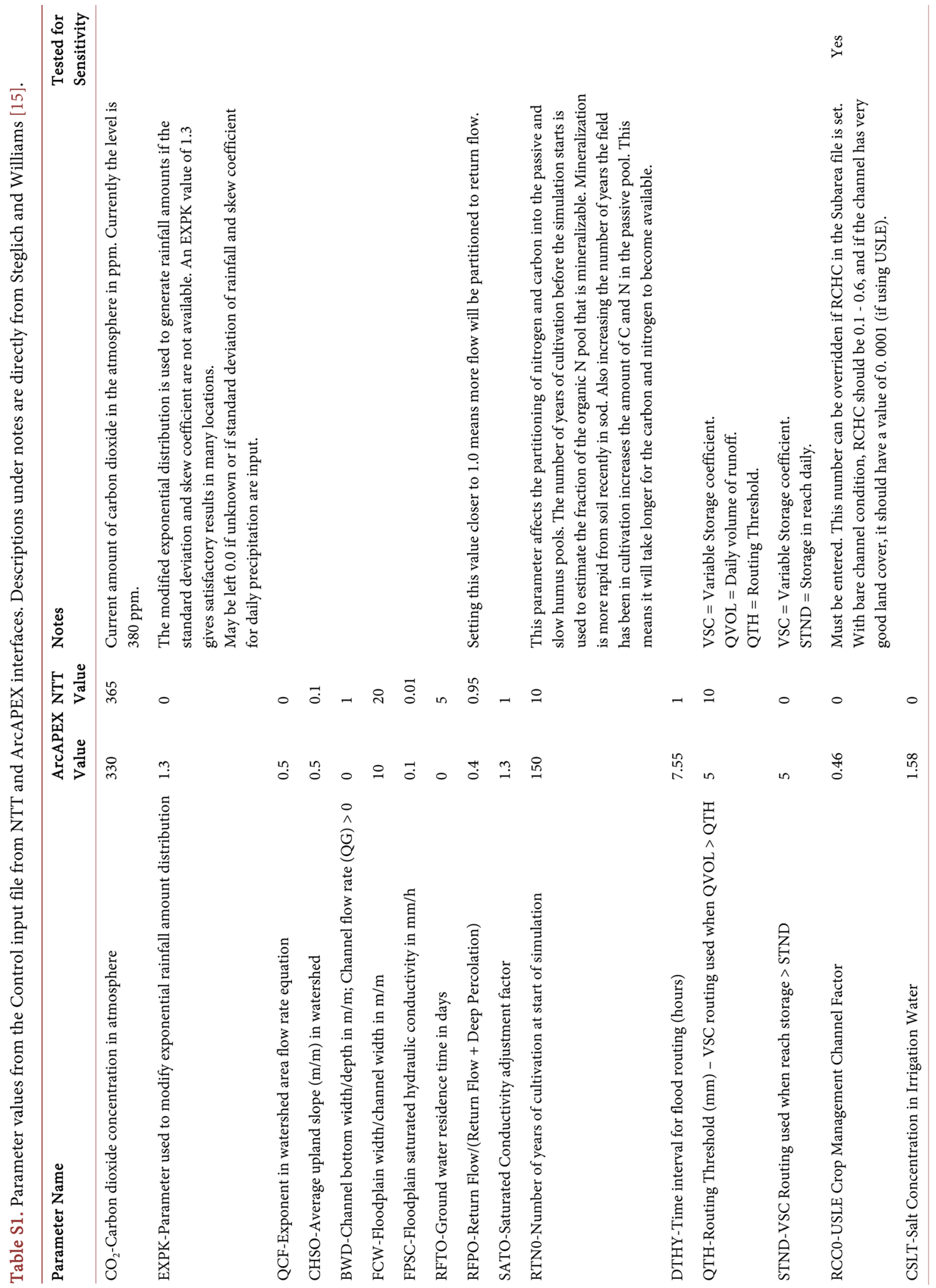




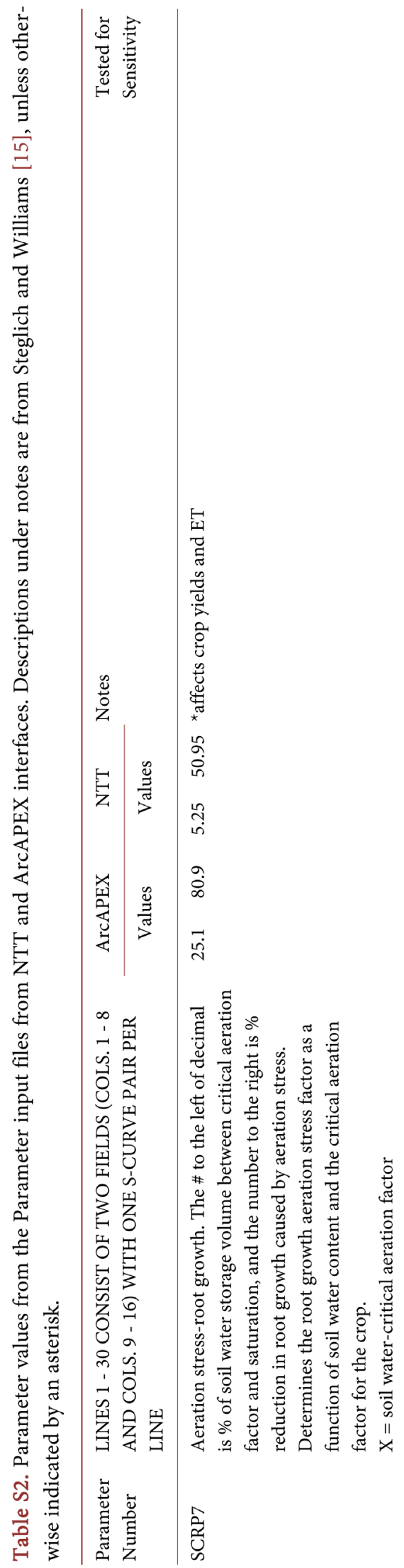

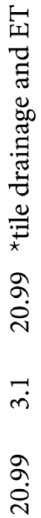

$\exists \quad \vec{i}$

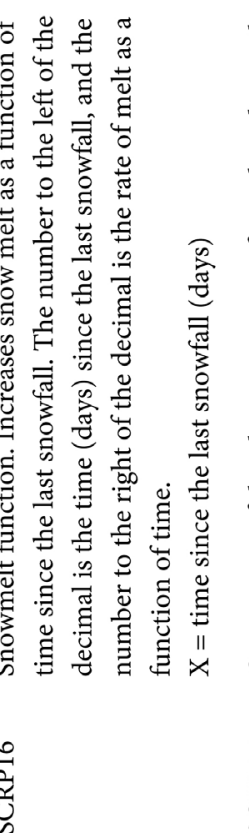

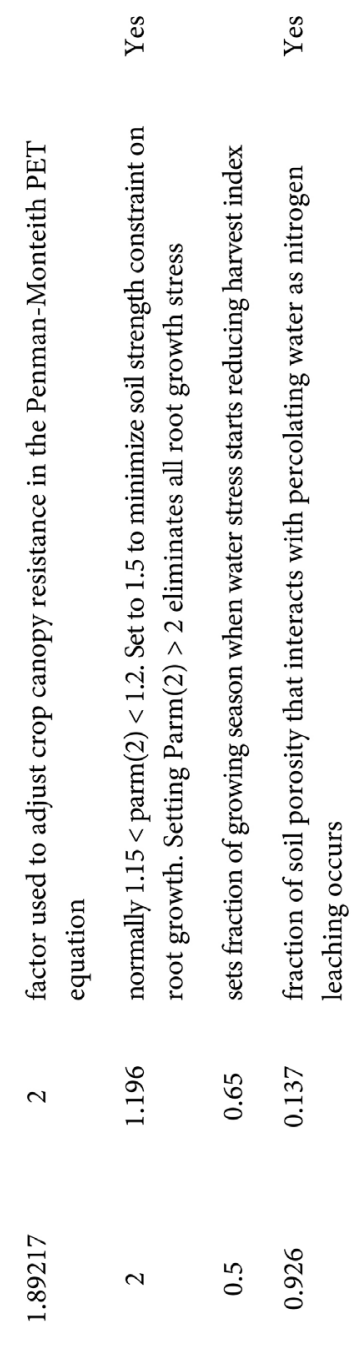

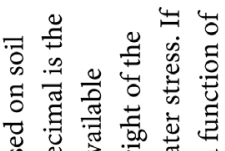

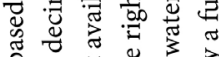

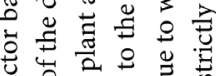

䒕苍 今

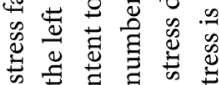

कै

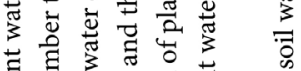

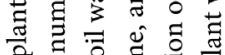

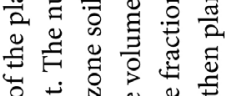

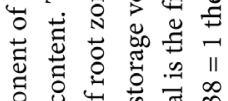

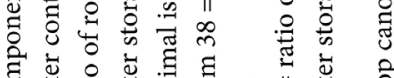

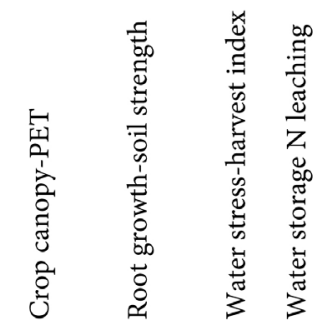

音 


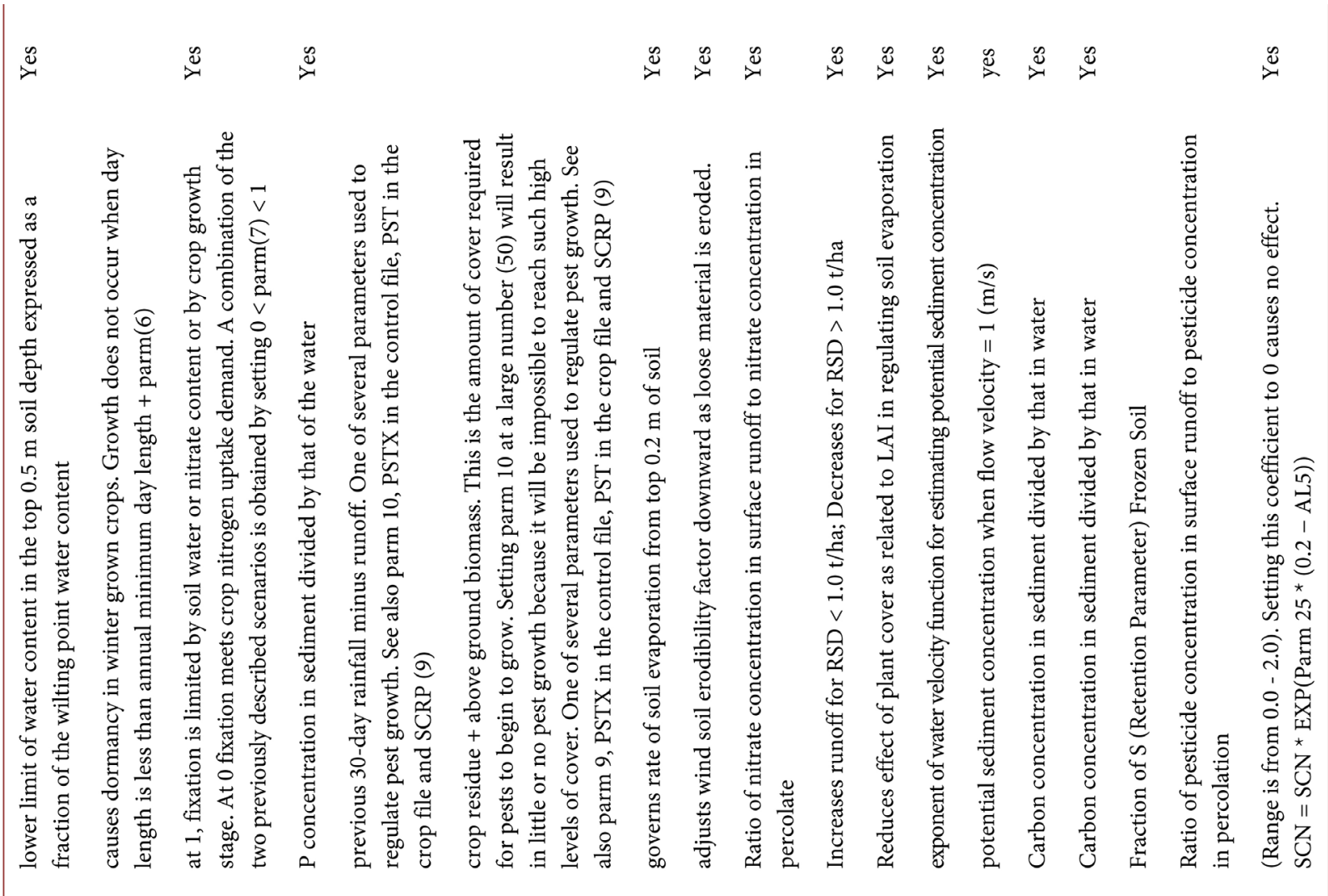

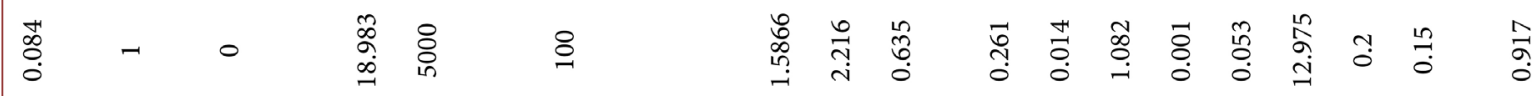

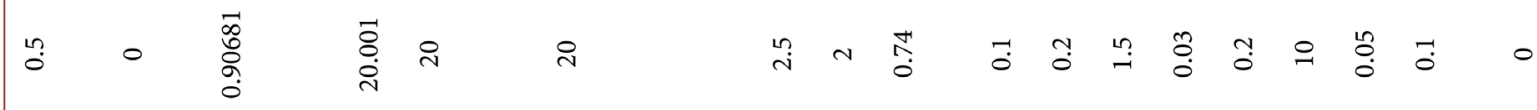

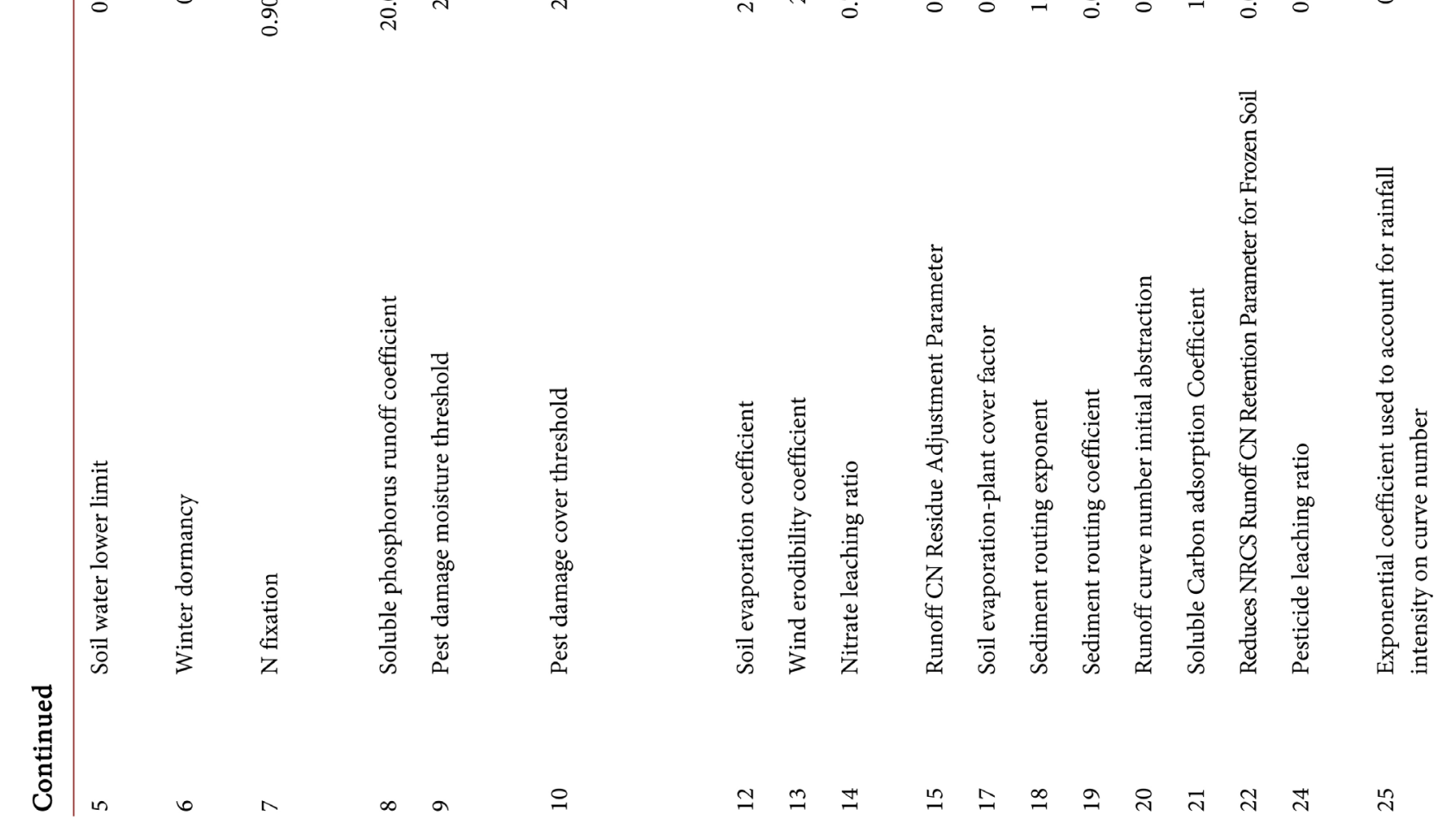




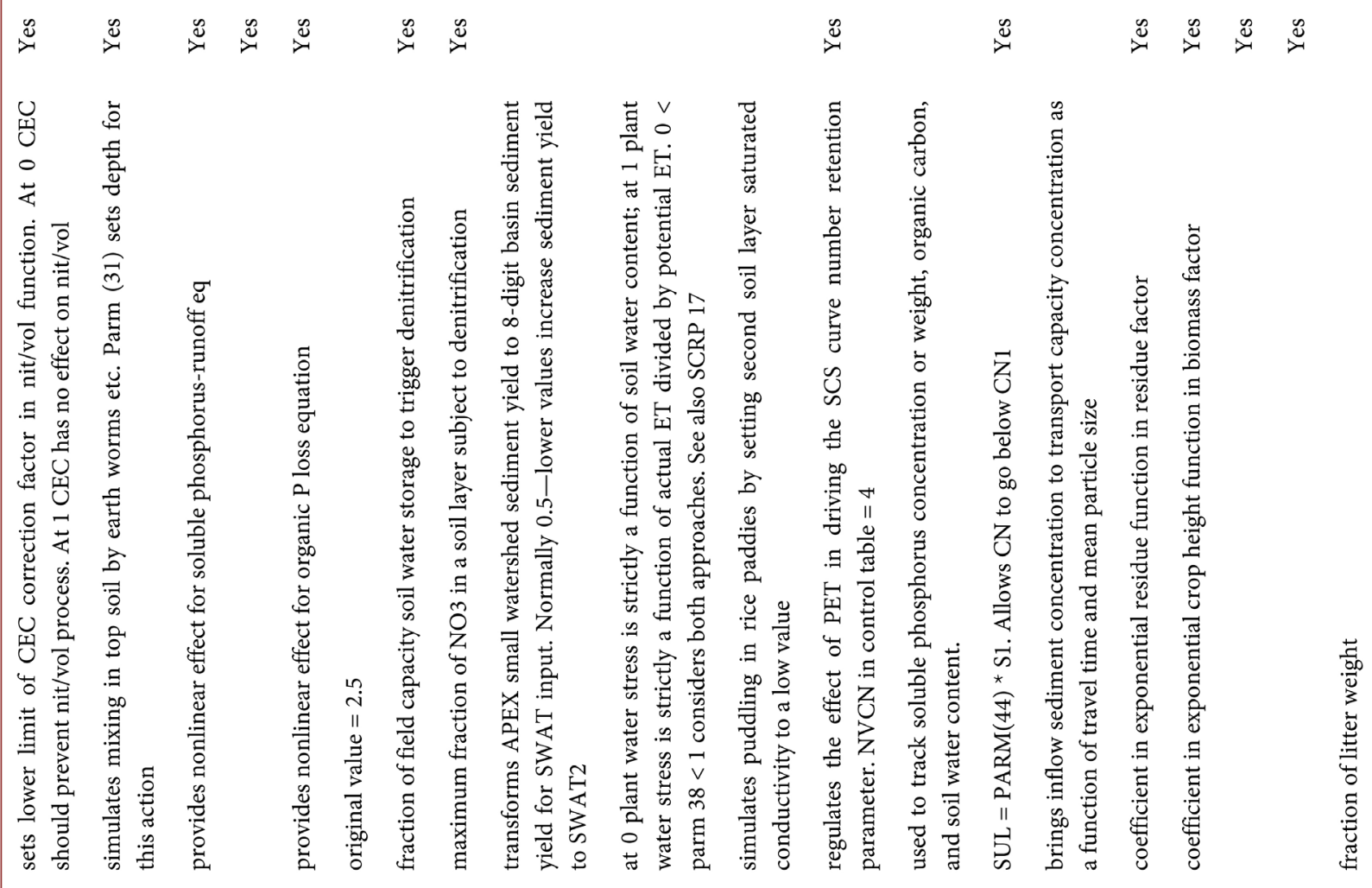

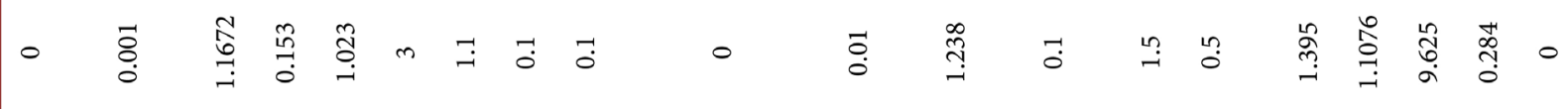

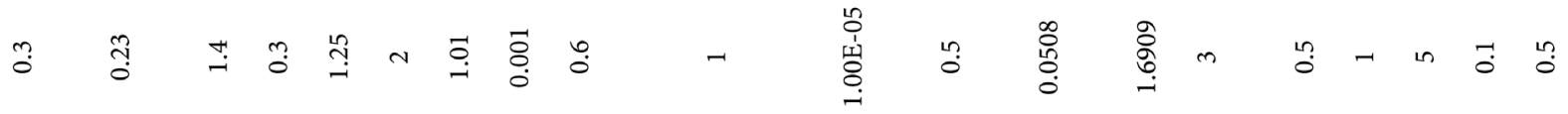

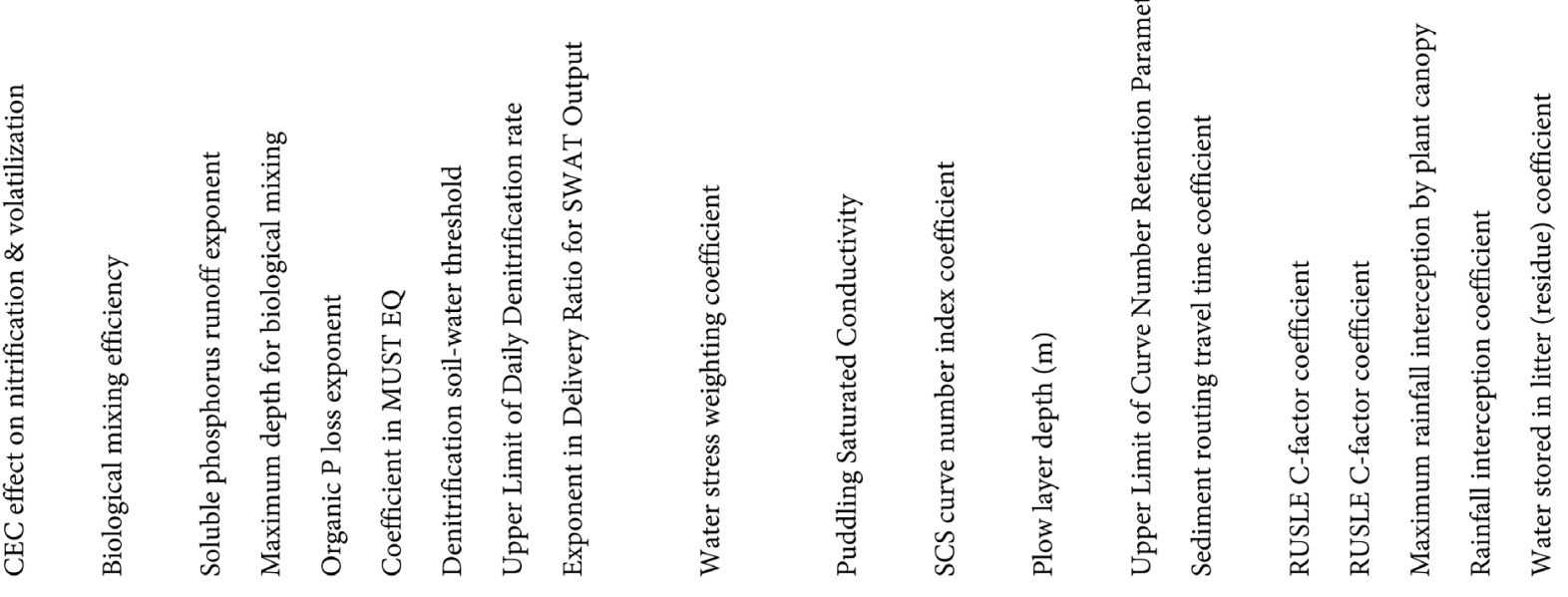




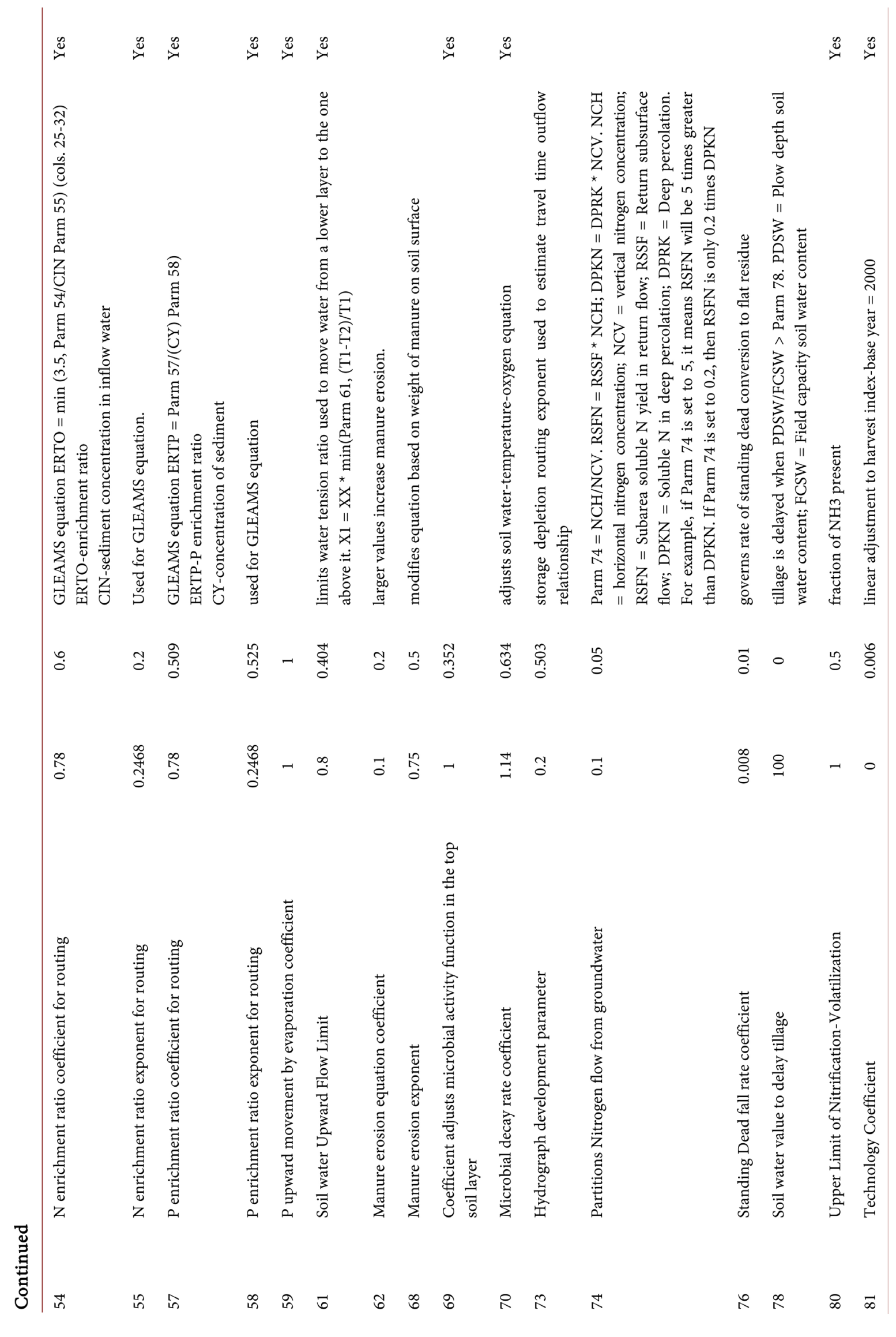




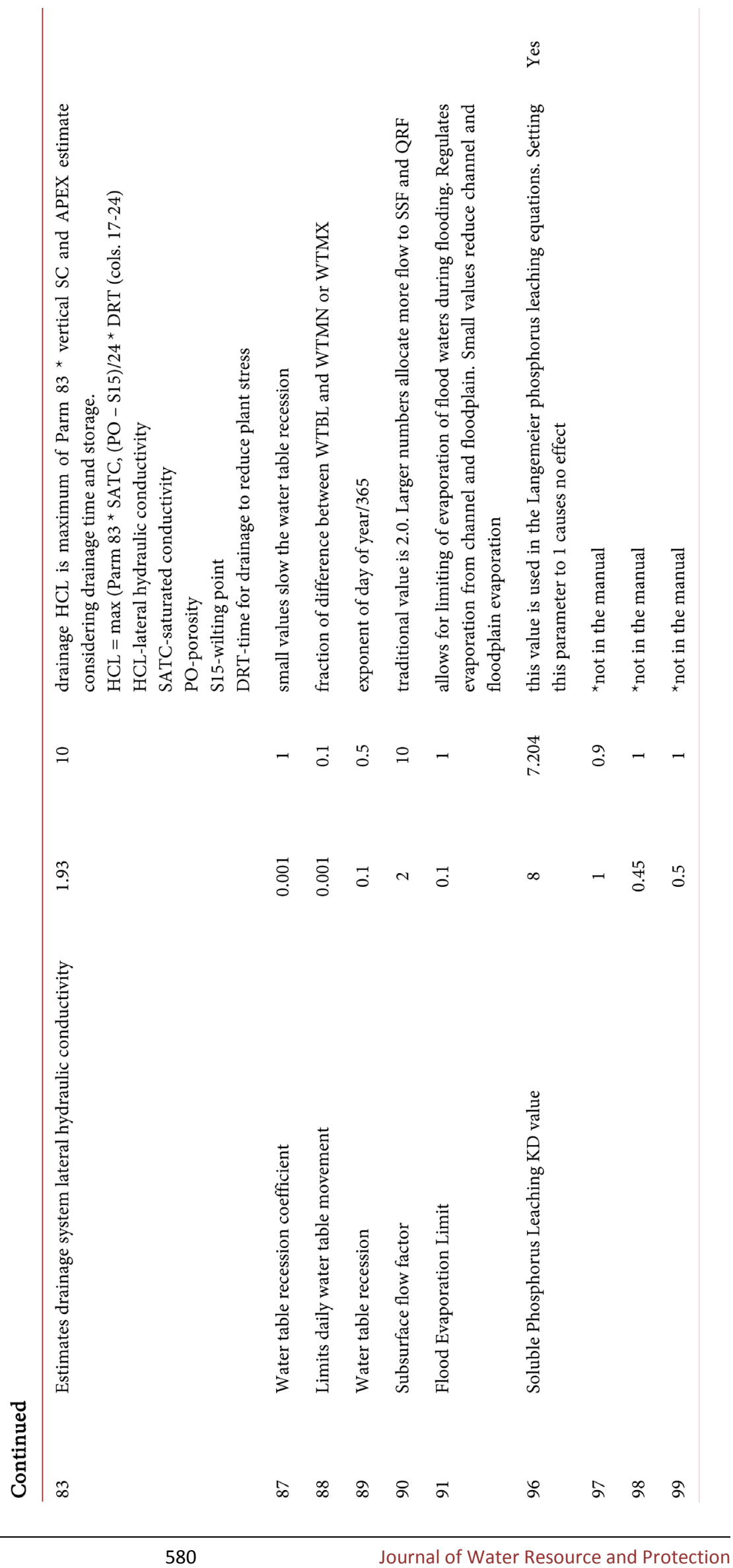

